\title{
Sanitary conditions of food establishments in Mekelle town, Tigray, north Ethiopia
}

\author{
Knife Zeru ${ }^{1}$, Abera Kumie ${ }^{2}$
}

\begin{abstract}
Background: Foodborne diseases are commonly found in developing countries like Ethiopia because of the prevailing poor food handling and sanitation practices. Food prepared in large quantities is liable to contamination and to the rise of foodborne diseases if the strictest principles of hygiene are not maintained.

Objective: The purpose of this study was to determine the sanitary conditions of food establishments in Mekelle town, Tigray region, North Ethiopia.

Methods: A cross-sectional study was conducted from November 2004 to January 2005. Four hundred and twenty establishments were enrolled through a simple random selection technique after a list of all food establishments was obtained through a census. Trained enumerators used standard and structured pre-tested questionnaires to collect data. Bacteriological tests were conducted on food utensils using standard laboratory procedures. Data entry, cleaning, and analysis were performed using Epi Info Version 6.04d.

Results: This study found that latrines, hand washing basins, proper types of solid waste receptacles, and privately owned tap water were available in $96.9 \%, 57.1 \%, 39.2 \%$ and $93.6 \%$ of the food establishments, respectively. Proper dish washing and food storage practices were observed in $46 \%$, and $52 \%$ of the establishments, respectively. Poor practices in personal hygiene among food handlers were commonly observed. Of all bacteriologically tested food utensils, $44.3 \%$ were found with aerobic mesophilic bacteria above the accepted level ( $>100$ colonies per plate) and $45.5 \%$ were grossly contaminated $(>50$ fecal coliform per $100 \mathrm{ml})$. Staphylococcus aurous and Escherichia coli were also isolated.
\end{abstract}

Conclusion and Recommendation: Overall findings of this study indicate the high likelihood of food contamination in food establishments in Mekelle. The study recommends that regulatory activities should be strengthened to ensure basic food sanitation practices in public food vending establishments in this town. [Ethiop.J.Health Dev. 2007;21(1):3-11]

Introduction

An adequate supply of safe, wholesome and health food is essential to the health and well-being of humans (1). However, at times, food itself can pose a health threat. The consumption of contaminated or unsafe foods may result in illness, also referred to as foodborne disease (2, 3). Foodborne diseases remain a major public health problem across the globe. The problem is severe in developing countries due to difficulties in securing optimal hygienic food handling practices. In developing countries, up to an estimated $70 \%$ of cases of diarrheal disease are associated with the consumption of contaminated food $(1,4)$. Reliable statistics on foodborne diseases are not available due to poor or non-existent reporting systems in most developing countries.

With the increase in urbanization, industrialization and tourism, mass catering establishments are becoming increasingly popular in both industrialized and developing countries. This dictates the need to ensure hygienic food handling and preparation practices in such public food establishments to safeguard the health and well being of consumers. Because food prepared in large quantities is more liable to contamination, there is a greater potential for the occurrence of foodborne disease outbreaks if basic sanitary practices are not maintained
(5). Reports of foodborne disease outbreaks in various countries have resulted from unhygienic food handling and preparation practices within food establishments (5, 6).

In countries where disease surveillance is well established, foodborne diseases are well monitored. There were about 737 outbreaks of foodborne diseases with a total of 52,011 cases reported to the Centers for Disease Control and Prevention (CDC). Thirty three percent of these outbreaks were related to food consumption in restaurants, cafeterias, and delicatessens (7). In England and Wales, the majority of cases, about $58 \%$, were associated with food prepared and served in restaurants, hotels, clubs, and other food establishments (6). Similar epidemiologic patterns were observed in foodborne outbreaks in Poland (4).

In Ethiopia, data on sanitation conditions and ensuing effects on health are very limited. Few studies conducted in Addis Ababa, Awassa, and Zeway indicate the prevailing poor sanitary conditions in mass catering establishments. Lack of cleanliness, inadequate sanitary facilities, and improper waste management were common features of catering establishments in these locales. These establishments commonly did not have adequate

\footnotetext{
${ }^{1}$ Tigray Regional Health Bureau. Tel: 0914-722288 (mobile); 034-4403110 (office), Email: <kinfezeru@yahoo.com>; ${ }^{2}$ Department of Community Health, Faculty of Medicine, Addis Ababa University; Email: aberakumie2@,Yahoo.com; Fax:+251-1-517701; Tel: 011-5157701; Mobile: 0911-882912
} 
facilities for washing utensils nor for clients to wash their hands $(8,9)$. Prevalence of intestinal parasitic infections and obvious forms of active skin and upper respiratory infections among food handlers in these establishments was $63 \%$ and $14.8 \%$, respectively $(9,10)$.

Various factors such as the general sanitary standards of the house, the proper use of sanitation facilities like latrines, hand-washing lavatories, refuse management systems, and dishwashing facilities affect food safety in food establishments. Food handling, preparation, and servicing practices are other important factors in determining the safety of food. Conditions of cooking utensils, food storage systems (time and temperature), as well as food handlers' knowledge and practices similarly affect food safety directly or indirectly $(6,11,12)$.

Mekelle, the capital town and political and economic center of Tigray Regional State, is presently experiencing rapid growth. As a result, the number of commercial food establishments in the city has been visibly increasing since 1991. The regional Health Bureau has undertaken various regulatory and promotional activities to decrease the threat of foodborne disease outbreaks from such establishments. The purpose of this study is to assess the hygiene knowledge and practice of food handlers, to examine the bacteriological quality of food utensils, and to determine the overall sanitary conditions of food establishments in Mekelle. This paper is expected to provide baseline data to inform regulatory efforts to improve sanitary conditions within food establishments.

\section{Methods}

A cross-sectional study was conducted from November 2004 to January 2005 in Mekelle town. The town has a population of 147,858 and is located $680 \mathrm{kms}$ north of Addis Ababa. An estimate of $62 \%$ of food establishments in this town are covered by the food hygiene inspection service.

All mass catering establishments within Mekelle, regardless of their legal status, constituted the source population for this study. Local establishments like "tela bet" and those that provide food and drink services during only select hours of the day were excluded from the study. A census was conducted in the town to obtain a complete list of existing catering establishments. The 546 establishments that were identified during this census served as the sampling frame. The establishments were stratified by the type of service they provide into the following strata: hotel, restaurant, bar, cafeteria, butcher shop, pastry shops, and juice vendor. The main purpose of stratification was to avoid over- or underrepresentation of certain types of establishments. A proportional sample size was determined for each stratum, and random selection was performed using a simple random table.
A sample size of 420 was calculated based on the assumption of overall poor sanitary conditions in $50 \%$ of establishments, $5 \%$ expected margins of error, $95 \%$ confidence level $\left(Z_{\infty / 2}\right)$ and $10 \%$ contingency for nonresponse. The $50 \%$ prevalence of unsanitary conditions was assumed in order to maximize the sample size.

About 66\% (277) of the study subjects (food establishments) rendered food services (breakfast, lunch and dinner) on a regular basis. One food handler per establishment $(\mathrm{n}=277)$ was selected for an assessment of knowledge and practice. Food handlers were randomly selected using a lottery method in the presence of one or more other food handlers in a kitchen or food preparation area.

Structured and pre-tested questionnaires were used to obtain information on socio-demographic characteristics of establishment owners/managers and food handlers, repair conditions of premises, availability of water supply, toilet facility, refuse management, dish washing facility and the like. The questionnaire also allowed the interviewers to record their observations.

Nine sanitarians and two senior sanitarians were recruited for data collection and supervision. Data collectors and supervisors were trained for 3 days on the purpose of the study, the format of the questionnaire, interviewing techniques, and data quality management. Data quality was also ensured by regular supervision, spot checking and reviewing the completeness and consistency of questionnaires on a daily basis. Data collectors (sanitarians) were assigned to collect data from establishments other than their permanent work place or catchment's area in order to minimize interviewer bias.

Eighty eight establishments (20\%) were randomly selected for bacteriological swab tests from the study subjects recruited for the overall assessment of sanitary conditions $(n=420)$. Bacteriological analyses of food utensils (food plates and bowls) were conducted to supplement the sanitary survey. Five plates and/or bowls were selected from each randomly enrolled establishment regardless of the scope and size of the establishments and the number of existing plates in each establishment. Utensils were selected from a stack of utensils that were shelved at the time of data collection, using a systematic selection technique.

Three medical laboratory technicians were recruited for the dish swab tests. Swabbing of plates, transportation, inoculation and isolation of the desired organisms was performed in a laboratory using standard procedures and culture medias as recommended $(13,14)$.

Ethical approval and clearance was obtained from respective authorities. Verbal consent was also obtained from establishment owners/managers and food handlers. 
Confidentiality was assured to all respondents. In case of major sanitary defects the owners/managers were advised for immediate correction. Data entry, cleaning and analysis were done using EPI INFO version $6.04 \mathrm{~d}$ statistical package. Frequency distributions, percentages and odds ratios (OR) with 95\% confidence level (C.I) were calculated for statistical significance tests.

\section{Results}

Socio-demographic characteristics of study population: The census identified 546 catering establishments, of which $422(77 \%)$ were enrolled in the study. Nonresponse rate was insignificant $(0.5 \%)$. A total of 420 mass catering establishments were investigated during the study, consisting of 51 (12.1\%) hotels, 55 (13.1\%) restaurants, $126(30 \%)$ bars, $114(27.1 \%)$ cafeterias, 54 $(12.9 \%)$ butcher shops, $13(3.1 \%)$ juice shops and 7 (1.7\%) pastry shops. Among these establishments 382 (91\%) were licensed. Two hundred seventy six $(65.7 \%)$ of the establishment owners were found operating their business in rented buildings. The majority, $410(97.6 \%)$ of the establishments were owned privately while 374 $(89 \%)$ were managed by the owners themselves.

The median years of service of the establishments was two years, ranging from one month to forty-eight years. Two hundred seventy seven (66.0\%) establishments were found to serve various types of meals including juices, cakes and bread, while the remaining 143 (34\%) establishments render only hot and cold drinks including alcohol.

The median age of owners/managers was 35 years, ranging from 19 to 80 years. The majority, 352(83.8\%) of the managers were literate. Half of the owners were married. Four hundred and ten (97.6\%) of the owners/managers were Christians and the remaining 10(2.4\%) were Muslims (Table1).

A sample of 277 food handlers was recruited for the knowledge and practice assessment out of a total of 1271 food workers (437 males and 834 females). I Two hundred eighteen $(79.7 \%)$ of the recruited food handlers were literate (grade one and above). Two hundred four (73.6\%) of the food handlers were female and 73 (26.4\%) were male. One hundred eighty eight $(67.9 \%)$ were single, 68(24.5\%) married, 11(4\%) divorced and the other $10(3.6 \%)$ were widowed. Their median age was 22 years with the youngest being 13 years and the oldest being 62 years of age. The median years of service was found to be one year, ranging from 10 months to 40 years and about half of the handlers had less than one year of service.

Physical conditions of food establishments: An assessment of sanitary conditions was conducted in $239(56.9 \%)$ establishments that had kitchens. The kitchen floors in 131(54.8\%) establishments were constructed of concrete, 58(24.3\%) floors were tile, $22(9.2 \%)$ were cement pointed stone, and the remaining $28(11.7 \%)$ were plain earth. On the other hand, $279(66.4 \%)$ dining/service room floors were constructed of tiles, $115(27.4 \%)$ were concrete, $23(5.5 \%)$ were cement pointed stone, and the remaining three were plain earth. One hundred forty four $(60 \%)$ kitchens and $345(82 \%)$ dining/service rooms had windows that could be opened (and average of about $10 \%$ of the floor area). Only $75(31.4 \%)$ of the kitchens had a dressing room for food handlers (Table 2).

\begin{tabular}{|c|c|c|}
\hline Characteristics & Frequency & Percent \\
\hline \multicolumn{3}{|l|}{ Sex } \\
\hline Male & 181 & 43.1 \\
\hline Female & 239 & 56.9 \\
\hline \multicolumn{3}{|l|}{ Age } \\
\hline $19-34$ & 198 & 47.1 \\
\hline $35-50$ & 177 & 42.1 \\
\hline$>50$ & 45 & 10.8 \\
\hline \multicolumn{3}{|c|}{ Educational status } \\
\hline Illiterate & 68 & 16.2 \\
\hline Grade 1-6 & 121 & 28.8 \\
\hline Grade $7-12$ & 170 & 40.5 \\
\hline Grade $>12$ & 61 & 14.5 \\
\hline \multicolumn{3}{|l|}{ Marital status } \\
\hline Single & 168 & 40.0 \\
\hline Married & 210 & 50.0 \\
\hline Divorced & 22 & 5.2 \\
\hline Widowed & 18 & 4.3 \\
\hline Separated & 2 & 0.5 \\
\hline \multicolumn{3}{|c|}{$\begin{array}{l}\text { Establishment building } \\
\text { ownership }\end{array}$} \\
\hline Owned & 144 & 34.3 \\
\hline Rented & 276 & 65.7 \\
\hline
\end{tabular}

The physical condition of establishments was assessed using a routine government sanitary inspection service. The cleanliness of floors, walls and ceilings as well as the availability of openable windows, and ventilation systems in establishments routinely inspected by government services were found to be in better conditions when compared to those that were not regularly inspected (Table 3 ).

Sanitary facilities of food establishments: The majority, $407(96.9 \%)$ of the establishments had toilet facilities. Only $35(8.6 \%)$ of those were found to have separate units for males and females. In 374(92\%) of the establishments the toilets were open for customers at the time of the assessment. A majority of establishments (95.6\%) used vacuum trucks to desludge full latrines. Other establishments constructed new latrines (10, 2.5\%), connected to the municipal storm water drainage (6, $1.5 \%)$, and two establishments $(0.5 \%)$ disposed to an excavated trench in their backyard. 
Table 2: The Physical Condition of Mass Catering Establishments, Mekelle, Tigray, December 2004

\begin{tabular}{lcc}
\hline \multicolumn{1}{c}{ Characteristics } & Frequency & Percent \\
\hline Kitchen, $\mathbf{n = 2 3 9}$ & & \\
Good floor repair condition & 149 & 62.3 \\
Good wall and ceiling repair condition & 130 & 54.4 \\
Clean walls and ceilings & 130 & 54.4 \\
Adequate ventilation & 165 & 69.0 \\
Adequate lighting & 185 & 77.4 \\
Dining room, $\mathbf{n}=\mathbf{4 2 0}$ & & \\
Good floor repair condition & 367 & 87.4 \\
Good wall and ceiling repair condition & 357 & 85.0 \\
Clean walls and ceilings & 350 & 83.3 \\
Adequate ventilation & 358 & 85.2 \\
Adequate lighting & 398 & 94.8 \\
\hline
\end{tabular}

Municipal pipe water was the only source of water supply for all establishments with 393 (93.6\%) establishments having access to privately owned water pipes. However, only $73(31.7 \%)$ of the kitchens had access to running tap water inside the facility for food preparation and utensil washing, and only $6(8.1 \%)$ had access to hot water supply.

Onsite solid waste storage containers/receptacles were available in 408(97\%) establishments. One hundred ninety one $(46.8 \%)$ receptacles were sacks, $143(35 \%)$ were barrels, 29 (7.1\%) were plastic buckets, 25 (6.1\%) were dustbins and the other 20 (4.9\%) were other types of temporary receptacles like cartons. More than one third $(38.1 \%)$ of the establishments had the proper type of receptacles: durable, tight fitting cover, and lightweight for easy lifting and transportation. Municipal refuse collection containers were the most common type of solid waste collection methods employed by 372 $(88.6 \%)$ of the establishments.

Table 3: The Repair and Ventilation Condition of Kitchens by Sanitary Inspection Status of Establishments in Mekelle, Tigray, December $2004(n=239)$

\begin{tabular}{lccc}
\hline Condition & \multicolumn{2}{c}{ Sanitary Inspection } & \multirow{2}{*}{ OR (95\% C.I) } \\
\cline { 2 - 3 } & Yes & No & \\
Kitchen wall and ceiling & 93 & 37 & $2.13(1.20,3.80)$ \\
$\quad$ Clean & 59 & 50 & 1.00 \\
$\quad$ Unclean & & & \\
Kitchen floor & 98 & 45 & $1.69(1.17,3.56)$ \\
$\quad$ Clean & 54 & 42 & 1.00 \\
$\quad$ Unclean & & & $1.11(0.62,1.98)$ \\
Openable window & 93 & 51 & 1.00 \\
$\quad$ Yes & 59 & 36 & \\
$\quad$ No & 110 & 55 & $1.52(0.83,2.79)$ \\
Kitchen ventilation & 42 & 32 & 1.00 \\
$\quad \begin{array}{l}\text { Adequate } \\
\text { Inadequate }\end{array}$ & & &
\end{tabular}

Lavatory facilities were available in 240 (57.1\%) establishments. Lavatory facilities consisted of buckets and welded metal sheets in 125 (52.1\%) establishments, conventional hand wash basins in 87 (36.3\%) establishments, and water troughs constructed of concrete and fixed with running tap water in 25 (10.4\%) establishments. . Detergents like soaps were available in $140(58.3 \%)$ of the lavatory facilities. A majority (87) of establishments disposed of their waste water/sullage generated from hand washing lavatories and dishwashing facilities into septic tanks or latrines (Table 4).

In addition, the ventilation condition of dining and/or service rooms, the repair condition of solid waste receptacles, and the availability of detergent (soap) in the hand washing lavatories were found to be in better conditions in those supervised establishments with an odds ratio of $1.78(95 \% \mathrm{CI}: 1.00,3.19), \mathrm{OR}=1.58(95 \%$ CI: $1.02,2.46)$, and $\mathrm{OR}=2.23(95 \% \mathrm{CI}: 1.25,3.97)$, respectively. The proportion of toilet facilities kept clean did not differ by whether or not the establishment had been inspected.

Among establishments which serve various types of meals and have kitchens, $232(97.10 \%)$ had some kind of dishwashing facility. Of these establishments 186 (80.2\%) used bowls and /or buckets for dish washing, $46(19.8 \%)$ used conventional types of sinks fixed with running tap water. One hundred seven (46.1\%) establishments used three-compartment dish washing facility, $112(48.3 \%)$ of establishments used two compartments and the remaining 13(5.6\%) establishments used a single compartment. The majority, $226(97.4 \%)$ of the establishments were found to use Ethiop.J.Health Dev. 2007;21(1) 
some kind of detergent for dish washing while 91(39.2\%) used hot water for sanitizing their dishes at least twice a week.

In addition, 390 (92.9\%) of the establishments had some kind of washing facility for drinking cups/glasses. About three fourth $(77.2 \%)$ of those establishments were equipped with a bowl and / or bucket for washing drinking cups, $89(22.8 \%)$ establishments used the conventional type of sink and $47(12 \%)$ used one compartment. Nearly half $(49.5 \%)$ of the establishments used two compartments for washing soiled cups and $150(38.5 \%)$ had washing devices with three compartments.

Table 4: Sanitary Conditions of Mass Catering Establishments, Mekelle, Tigray, December $2004(n=420)$

\begin{tabular}{lcc}
\hline \multicolumn{1}{c}{ Characteristics } & Frequency & Percent \\
\hline Water supply & 393 & \\
Pipe private & 16 & 93.6 \\
Pipe shared & 11 & 3.80 \\
Pipe from neighbors & 321 & 2.6 \\
Latrine facility & 86 & 76.4 \\
$\quad$ Flush type & 13 & 20.5 \\
Dry pit latrine & & 3.1 \\
$\quad$ Not available & 278 & 68.3 \\
Latrine condition & 129 & 31.7 \\
$\quad$ Properly managed & & \\
Improperly managed & 34 & 8.1 \\
Liquid waste final disposal & 366 & 87.1 \\
Open area dumping & 17 & 4.1 \\
To septic tank/latrine & 3 & 0.7 \\
To municipal storm water drainage & & \\
Others & 160 & 38.1 \\
Solid waste storage receptacles & 248 & 59.0 \\
Proper receptacle available & 12 & 2.9 \\
Improperly stored & & \\
$\quad$ Not available & 372 & 88.6 \\
Solid waste collection and disposal & 6 & 1.4 \\
$\quad$ Municipal container & 28 & 6.7 \\
On site disposal & & 3.3 \\
$\quad$ Privately owned carts & & \\
$\quad$ Others (open field dumping, & 14 & \\
dumping into storm water drainage) & &
\end{tabular}

Knowledge and practice of food handlers on food hygiene: There were 277 food and drinking establishments that provided food services regularly. Among the 277 food handlers who were interviewed for the knowledge and practice assessment, 248 (89.5\%) knew at least one type of foodborne disease. Mass media was the most common $(50 \%)$ source of information, followed by health centers $(42.7 \%)$. The proportion of food handlers who believed that foodborne diseases are caused by germs was $197(79.4 \%)$. Of those who were asked about the mode of transmission of foodborne disease, 207(83.5\%) answered that contaminated food was the vehicle and $138(55.6 \%)$ responded that vectors are the channels for the transmission. Eighty three percent (206) of the food handlers also knew the potential risk of contaminating food by having dirty hands (Table 5).

In 181(65.3\%) kitchens, prepared local foods like "Enjera" and "wet' were kept in clean containers and covered properly. In nearly half (48.7\%) of the kitchens, food utensils and equipment were stored properly at the time of the survey. Two hundred and one (72.6\%) of the food handlers were found wearing outer working garments, $67(33.3 \%)$ of which were not clean. One hundred and eight (39\%) were found with covered hair, and $211(76.2 \%)$ were with trimmed fingernails and 99(35.7\%) were found preparing food while they wore finger ornaments. Only 63 (22.7\%) food handlers had had medical check ups in the past year. Diarrhea, respiratory infection, skin lesion and nose and eye discharges were observed in $25(9 \%)$ of the food handlers.

Inspection of food establishments by responsible authorities seemed to have a positive influence on the sanitary conditions of the establishments. It was found that those establishments who had been inspected were more likely to comply with accepted hygienic practices (Table 6).

Bacteriological test results: Among the 420 establishments selected for the overall sanitary condition assessment, 88 establishments were enrolled for swab 
tests. Nineteen $(21.6 \%)$ of the samples were collected from hotels, 39 (44.3\%) from restaurants, 29 (33\%) from cafeterias and a single swab from a bar. Eighty two $(93 \%)$ of the establishments wiped their utensils using cloth or towel. Clean food utensils were stored in cupboards $(15,17 \%)$, shelves $(16,18.2 \%)$ and on simple tables without covers $(57,64.8 \%)$

Table 5: Food Handlers' Knowledge of Foodborne Diseases, Mekelle, Tigray, December 2004 (n=277)

\begin{tabular}{lcc}
\multicolumn{1}{c}{ Knowledge } & Frequency & Percent \\
\hline Heard about foodborne diseases & 248 & 89.5 \\
Have not heard about foodborne diseases & 29 & 10.5 \\
Causes of foodborne diseases & & 79.4 \\
$\quad$ Germs & 197 & 1.6 \\
Chemicals & 4 & 25 \\
$\quad$ Unhygienic food preparation & 62 & 1.6 \\
$\quad$ Anger of God & 4 & 83.5 \\
Mode of foodborne disease transmission & & 35.5 \\
Contaminated food & 207 & 55.6 \\
Contaminated water & 88 & 83.1 \\
Vectors like flies and cockroaches & 138 & 18.5 \\
Reason for food contamination & & 61.3 \\
$\quad$ Dirty hands & 206 & 31.5 \\
Infected food handlers & 46 & 22.6 \\
Unclean/dirty utensils & 152 & 78 \\
Dirty working area & 56 & \\
Infestation of insects and rats & 5677
\end{tabular}

$\underline{\text { N.B: }}$ Because of the possibility of multiple responses total number of food handlers may not be equal to 277

A total of 78 plates and 13 bowls were examined for bacteriologic content. . Based on observations with the naked eye, 56(63.6\%) utensils were new and tidy, $25(28.4 \%)$ were old and stained, and the remaining $7(8 \%)$ were found corroded and cracked.

Aerobic Mesophilic Bacteria (viable bacteria), Escherichia Coli, Staphylococcus aureus as well as total and fecal coliform were isolated. Aerobic mesophilic bacteria were found in 69(78.4\%) of the swabbed utensils with an average of 53 colonies per utensil. Forty four percent of the swabbed utensils were found to contain cultures of aerobic mesophilic bacteria above the acceptable level ( $>100$ colonies/utensil). S.aureus and E.coli were isolated from $24(27.3 \%)$ and $16(18.2 \%)$ of the swabbed utensils, respectively. Acid and gas formation in $69(78.4 \%)$ of the examined utensils confirmed the presence of total and fecal coliform.

Overall sanitary condition: It was found difficult to rate the sanitary condition of establishments as good or bad due to the lack of a standard grading tool and/or reference material. However, the study selected a few variables to rate sanitary conditions. The selected variables were floor repair condition, infestation of flies, toilet availability and cleanliness, availability of hand washing lavatories, physical condition of solid waste storage containers, and availability of a private pipe water supply. The presence of these factors as per hygienic provisions was rated as acceptable. Using the above variables, only $72(17.1 \%)$ of the surveyed establishments had good sanitary conditions. Cross tabulations were run to test for any associations between the variables. Establishments in privately owned buildings and regularly inspected establishments were more likely to be in good sanitary condition $[\mathrm{OR}=2.93$, 95\% CI: $1.68,5.18$ and $\mathrm{OR}=3.56,95 \% \mathrm{CI}: 1.81,7.14$, respectively] than those establishments that were rented and not regularly inspected. Establishments with managers with an education level above grade six were also determined to be in good sanitary condition [(OR, 95\%CI: $1.80(1.03,3.18)]$.

Sanitary conditions were compared across each stratum by the selected variables mentioned above. As a result 23 (45\%) hotels, $21 \quad(38.2 \%)$ restaurants, $23 \quad(20.2 \%)$ cafeterias, $4(7.4 \%)$ butcher shops and a single bar were found in good sanitary condition. On the other hand, neither the juice shops nor pastry shops met the selected criteria. 


\begin{tabular}{|c|c|c|c|}
\hline \multirow[b]{2}{*}{ Characteristics } & \multicolumn{2}{|c|}{ Sanitary inspection } & \multirow[b]{2}{*}{ OR (95\% C.I) } \\
\hline & Yes & No & \\
\hline \multicolumn{4}{|l|}{ Storage of food utensil } \\
\hline Proper & 103 & 32 & $2.36(1.35,4.11)$ \\
\hline Improper & 82 & 60 & 1.00 \\
\hline \multicolumn{4}{|l|}{ Storage of ready-to-eat foods } \\
\hline Proper & 131 & 50 & $2.04(1.17,3.56)$ \\
\hline Improper & 54 & 42 & 1.00 \\
\hline \multicolumn{4}{|l|}{ Food Handler wears gown } \\
\hline Yes & 142 & 59 & $1.85(1.03,3.32)$ \\
\hline No & 43 & 33 & 1.00 \\
\hline \multicolumn{4}{|l|}{ Food Handlers gown } \\
\hline Clean & 102 & 32 & $2.15(1.09,4.26)$ \\
\hline Not clean & 40 & 27 & 1.00 \\
\hline \multicolumn{4}{|c|}{ Food handler with trimmed finger nails } \\
\hline Yes & 144 & 67 & $1.31(0.70,2.44)$ \\
\hline No & 41 & 25 & 1.00 \\
\hline
\end{tabular}

\section{Discussion}

This study revealed that the proportion of catering establishments in Mekelle operating with a license certificate was greater than the findings of similar studies conducted in Addis Ababa and Zeway $(8,9)$, but similar to those in Awassa (10). This could be due to the integrated effort of concerned regulatory organizations, Kebele leaders, and sanitary guards to enforce rules and regulations of the regional government.

It is compulsory for food establishments to maintain good repair and clean housing conditions to safeguard food against contamination (11). The findings of this study indicate that while dining/service rooms tend to be clean and well repaired, food preparation areas and kitchens were unclean and not well repaired. However, these findings indicate better results than those in previous studies (8-10). The discrepancy in the physical status of the kitchen and food service areas is explained by the differences in the conformity to housing sanitation requirements. The majority of food establishments were initially intended for residence sites and were later converted into mass catering establishments without consideration of and adherence to sanitation requirements. The lack of awareness on the regulatory provisions and weakness in the licensing enforcement can also explain the differences.

The percentage of establishments in Mekelle with toilet facilities $(97 \%)$ was comparable to the percentage in Awassa (95\%), but higher than that observed in Addis Ababa (86\%) (8-10). However, nearly one third (31.7\%) of the available latrines were improperly managed. Lavatory facilities were available only in $57.1 \%$ of the establishments, most of which were in establishments providing meal services. The absence of lavatory facilities in a large number of establishments, particularly in those that did not provide meal services indicates the lack of stringent licensing procedures.
Although the majority of the establishments (97\%) had some kind of refuse storage receptacle, most did not comply with the acceptable specification for receptacles (15). Nearly half of the observed receptacles were sacks and cartons, which are insufficient and unsanitary as they are prone to spillage and serve as good breeding grounds for flies that can then contaminate food.

There are varied reasons for the use of inappropriate typed of refuse storage receptacles by many establishments. While the owners/managers may not be knowledgeable about the sanitary importance of using appropriate types of storage containers, the regulatory provisions during the inspection of food establishments may not be strict enough to reinforce compliance.

One of the most widely used and accepted methods of washing food utensils is the three compartment sink or vat system $(11,15)$. However, less than half of the establishments washed their food utensils using this method. About $46 \%$ of the establishments, among those which had kitchen and serve meals, and $38.5 \%$ of the establishments among all that served meals, hot and cold drinks, used three compartments to wash utensils. Though the practices in Mekelle are better than the washing practices in Addis Ababa and Zeway $(8,9)$, they fall short of meeting the sanitary criteria and require further improvement.

Food handlers had reasonably good knowledge of the cause, mode of transmission, and the risk factors for food contamination and foodborne diseases. However, their high level of knowledge did not correspond with the poor sanitary conditions of the facilities in which they worked, particularly with the cleanliness and repair conditions of the kitchens and food utensils, as well as the uncleanly storage of prepared foods and food utensils. This discrepancy between knowledge and practice my be explained by a few factors including reluctance to practice what they know due to negligence and lack of

Ethiop.J.Health Dev. 2007;21(1) 
attitudinal change, and lack of encouragement.. They might also not be equipped and/or supplied with the necessary materials that would enable them to maintain the sanitary quality of their premises. Generally, the weak enforcement of sanitary provisions is a contributing factor to the overall poor sanitary condition of food establishments.

All food handlers have a basic responsibility to maintain a high degree of personal cleanliness and observe hygienic and safe food handling practices; otherwise they can contaminate food sources with pathogenic microorganisms (7). In this study food handlers' personal hygiene standards and food handling practices were found unsatisfactory. In addition, the study observed a small proportion of food handlers (9\%) preparing food while sick. This makes the spread of foodborne diseases highly like in such establishments, unless corrective sanitary measures are put in place.

Regular monitoring and control of establishments by the responsible regulatory body had a positive influence on the personal hygiene and food handling practices of food handlers. Establishments whose kitchens had been inspected had better storage conditions for prepared foods and food utensils, cleaner kitchen walls and ceilings, and a higher proportion of food handlers with trimmed fingernails and outer working garments when compared to establishments that had not been inspected. This finding was consistent with similar studies done in Addis Ababa $(8,9)$.

The presence of S.aureus, coliform like E.coli and aerobic mesophilic bacteria (AMB) colonies above 100 per plate shows the existing poor sanitary quality of food utensils (6). In this study, the bacterial indicators showed the unhygienic condition of food utensils. Ineffective washing techniques, improper handling and storage of clean utensils, rare changing of water used for washing plates, and use of dirty cloths/towels to wipe and dry plates are some of the factors that could contribute to the gross contamination. Food handlers with skin lesions, respiratory infection and nose and eye discharge could have served as the source point for the presence of S.aureus on the plates. As S.aureus lives and flourishes in the human nose, throat and skin, the likelihood of recontamination of cleaned plates by infected food handlers is quite high.

Individual hygienic indicators can be used to evaluate the sanitary conditions of food establishments but they may not provide a full picture of the situation and may provide a biased assessment. Composite measurements used in this study clearly indicate that only less than $20 \%$ of the study subjects confirm hygienic norms. This is unacceptable practice given the circumstances that foodborne diseases are prevalent in urban settings.

\section{Conclusions and recommendations}

In general, we can conclude that food establishments in the study area were found to have poor sanitation and were not maintained well. Specifically, the study identified the following major sanitary deficiencies: poor repair condition of kitchens, improperly managed toilet facilities, inappropriate solid waste receptacles, lack of standard dish washing compartments, and lack of hand washing lavatories in a large number of establishments. The bacteriological swab tests of food utensils confirmed the gross unhygienic condition of food establishments. Despite food handlers' high level of knowledge of sanitary practices, their personal hygiene and food handling practices were also unsatisfactory. Thus, the likelihood of food contamination is very high in food establishments of Mekelle town. The provision of regular sanitary inspection had a positive impact in improving the hygienic status of food and drinking establishments.

Based on the study findings, we recommend that the regulatory body pay due attention to strengthening the compliance of mass catering establishments to acceptable sanitary conditions in general, and food hygiene in particular. The public's access to standard sanitary facilities should get closer consideration. There is also a need to immediately and unconditionally intervene with sick food handlers working in food establishments. It is advised that food handlers receive medical check ups and also receive information and educational materials that can improve their food handling practices.

\section{Acknowledgement}

We are grateful to the Tigray Regional Health Bureau for financing this research project. Our sincere acknowledgement goes to Addis Ababa University, Department of Community Health for the opportunity we had to conduct this study. Gratitude is also deeply expressed to Environmental Health Workers and Medical laboratory Personnel who participated in data collection and swab test examination. Establishment owners/managers and food handlers are appreciated for their interest and full participation shown in the study.

\section{Reference}

1. WHO. Guidelines for Establishing or Strengthening National Food Contamination Monitoring Programmes. WHO, Geneva, 1979.

2. WHO. World Health Organization global strategy for food safety: safer food for better health. 07 September $2004<$ <ttp://www.who.int/foodsafety// publications/general/en / strategy_en.pdf $>$

3. H/Mariam T. and Demisse A. Livestock Marketing Authority: A paper Presented on the Occasion of the National Food Safety Conference. Addis Ababa. November 2002.

4. WHO. Foodborne Disease: A focus for Health Education. 2000. 
5. Charles R.H.G. Mass Catering. WHO Regional Publication, European Series No.15 1983.

6. Hobbs Betty C. and Roberts Diane. Food Poisoning and Food Hygiene. 1987

7. Salvato Joseph A. Environmental Engineering and Sanitation. Fourth Edition. A Wiley Interscience publication, John Wiley \& Sons INC, New York, 1992.

8. Fisseha G. Berhane Y. and Teka GE. Public Catering Establishments in Addis Ababa: Physical and Sanitary Facilities. Ethiop. J. Health Dev. 1999; 13(2): 127-134.

9. Kumie A, Genete K, Worku H, Kebede E, Ayele F and Mulugeta $\mathrm{H}$. The Sanitary Conditions of Public Food and Drink Establishments in the District town of Zeway, Southern Ethiopia. . Ethiop. J. Health Dev. 2002; 16(1): 95- 104

10. T/Mariam S, Roma B, Sorsa S, Worku S, and Erosie L. Assessment of Sanitary and Hygiene status of Catering Establishments of Awassa Town. Ethiop. J. Health Dev. 2000; 14(1):91-98.
11. Gebre-Emanual T. Public Food Service Establishment Hygiene. In: Food Hygiene: Principles and Methods of Foodborne Diseases Control with Special Reference to Ethiopia. Faculty of Medicine, Department of Community Health Addis Ababa University, 1997.

12. Factors leading to Microbial foodborne Illnesses. 08 July $\quad 2004 \quad<$ http://www.who.int/foodsafety/ publications/capacityen /3.pdf $>$

13. U.S.A. Department of Health, Education and Welfare. Public health Service: Procedures for the Bacteriological Examination of food Utensils and/or food Equipment Surfaces. Technical Information Bulletin No.1 June 1967: 1-7.

14. Senior BW. Examination of Water, Milk, Food and Air. In: Collee J.G., duguid J.P., Fraser A.G. and Marmion B.P. Mackie and McCartney: Practical Medical Microbiology, $13^{\text {th }}$ edition, Churchill Livingston, 1989;204-239

15. Tigray Regional Health Bureau. Basic Criteria for Hygiene and Environmental Health service for Establishments; January 1997. 